\title{
0 olhar de futuros pais sobre o processo de adoção
}

\author{
The sight of future parents about the adoption process
}

\author{
Luana Tainá Mesquita Costa ${ }^{[a]}$, Verônica Suzuki Kemmelmeier ${ }^{[b]}$
}

\footnotetext{
[a] Discente do Curso de Psicologia da Universidade Estadual do CentroOeste (Unicentro), Irati, PR - Brasil e-mail: luanacosta1@hotmail.com

${ }^{[b]}$ Mestre em Educação pela Universidade Federal do Paraná (UFPR), docente na Universidade Estadual do Centro-Oeste (Unicentro), Irati, PR - Brasil, e-mail: veronicask@uol.com.br
}

Recebido: 29/03/2011

Received: 03/29/2011

Aprovado: $14 / 04 / 2011$ Approved: 04/14/2011

\section{Resumo}

Este artigo buscou identificar os sentimentos vivenciados pelos pais durante a espera da adoção, período marcado por diversas dificuldades. Trata-se de uma pesquisa empírica em que seis participantes foram entrevistados, dois casais e duas irmãs, sendo que apenas um dos casais já possuía filhos biológicos. Esses participantes constituíam o Grupo de Apoio a Pais na Fila de Espera da Adoção, da cidade pesquisada. Foram realizadas entrevistas semiestruturadas em dois momentos, inicialmente de maneira individual e, posteriormente, com os pares. Os resultados obtidos foram organizados em categorias, visando classificar os sentimentos relacionados ao motivo de adotar, o gestar na fila de espera e o perfil desejado dos filhos pelos participantes. Considera-se, desse modo, a importância do acompanhamento dos pais por uma equipe preparada, pois a visão dos adotantes, muitas vezes, é afetada por fatores encobertos que tornam o processo de adoção pouco compreensível para esses indivíduos.

Palavras-chave: Adoção. Pais adotantes. Fila de espera. Filhos adotivos.

\section{Abstract}

This article aimed to identify the feelings experienced by parents while waiting for adoption, a period marked by various difficulties. This is an empirical study in which six individuals were interviewed - two couples and two sisters - and only one of the couples already had biological children, such participants formed the Support Group for Parents in the Queue of Adoption of the city investigated. Semi-structured interviews were conducted in two phases, initially individually and subsequently with pairs. The results were organized into categories in order to classify the feelings related to the why adopting, gestating in the queue and the profile of children desired by the participants. Thus, it is considered the importance of parental monitoring by a team prepared, since the sight of adopters is often affected by underlying factors that make the adoption process little understood by them

Keywords: Adoption. Adoptive parents. Waiting queue. Adoptive children. 


\section{Introdução}

A sociedade contemporânea vem, aos poucos, empregando temas referentes à adoção como ponto de partida para diferentes debates, incluindo e normalizando essa cultura dentro das novas configurações familiares. Como assinalam Costa e Rossetti-Ferreira (2007), as diversas mudanças sociais e legislativas favorecem essas novas práticas de adoção e as novas concepções familiares. E é a partir dessa perspectiva que vemos emergir no país um movimento de cultura de adoção.

Diante das afirmativas supracitadas, deparamo-nos com o que é compreendido por adoção na atualidade, para que, a partir dessas informações, o processo seja verificado em sua totalidade. 0 artigo 19 do Estatuto da Criança e do Adolescente dispõe que: "Toda criança ou adolescente tem direito a ser criado e educado no seio de sua família e, excepcionalmente, em família substituta, assegurada a convivência familiar e comunitária, em ambiente livre da presença de pessoas dependentes de substâncias entorpecentes" (Brasil, 1990).

Sendo assim, todo sujeito menor de 18 anos tem direito a uma família suplente, que garanta o convívio familiar e comunitário. Isso pode ocorrer por meio de diferentes medidas, a saber: tutela, guarda ou adoção. Essas ações têm como apoio a legislação e o advento dos Juizados da Infância e da Juventude, os quais atualmente têm como legislação vigente desse assunto a Constituição Federal, o Estatuto da Criança e do Adolescente (ECA), o Código Civil Brasileiro e a Lei n. 12.010/2009 (Brasil, 2009).

Nesses diferentes documentos, os direitos básicos da criança e do jovem são garantidos. De acordo com o ECA, Lei n. 8.069 (Brasil, 1990), são evidenciados os interesses do adotando (filho), estabelecendo como principal objetivo do processo de adoção assegurar o seu bem-estar, conforme dispõe o artigo 43: "A adoção será deferida quando apresentar reais vantagens para o adotando e fundar-se em motivos legítimos". Isso pode ser relacionado ao conceito da nova cultura de adoção implantada, ao contrário do modo clássico, que buscava uma criança para satisfazer o desejo de se ter um filho (Weber, 2008).

E é justamente a atribuição como filho que denota a adoção, pois de acordo com o ECA (Brasil, 1990), a colocação de uma criança ou adolescente em uma família substituta lhe concede a condição de filho. "A adoção atribui ao adotado a condição de filho, com os mesmos direitos e deveres, inclusive sucessórios, desligando-o de qualquer vínculo com pais e parentes, salvo os impedimentos matrimoniais" (Brasil, 1990, Art. 41).

A partir de tal colocação, tem-se que a adoção é irrevogável, dando ao adotado os mesmos direitos do(s) filho(s) biológico(s). No registro civil do adotado, os nomes que constarão como pais e seus ascendentes, são os dos adotantes, considerando que nenhuma informação sobre sua "real" origem deverá existir na certidão (Campos \& Costa, 2004).

Apesar de tais alterações nas leis do Estado, é necessário que todos os aspectos da sociedade em que o processo de adoção está envolvido tenham um olhar detalhado e cuidadoso, pois ainda perpassam muitos preconceitos em função de representações sociais, religiosas, econômicas e até mesmo políticas nesse âmbito. Para tanto, algumas noções do que é, e de como ela se sucede devem ser apresentadas a fim de que a adoção seja compreendida.

Partindo-se dessas informações, normas gerais para o processo são estabelecidas (Brasil, 1990), tais como:

a) a idade mínima dos candidatos a adotantes é de 18 anos, possuindo diferença de idade mínima de 16 anos em relação aos adotados;

b) ascendentes (avós, bisavós) e descendentes (filhos, netos) não podem adotar seus parentes;

c) o estado civil do adotante não é relevante;

d) a adoção requer a concordância dos pais biológicos, salvo em caso de paternidade desconhecida ou quando estes tiverem perdido o poder familiar (soma de deveres e direitos assumidos pelos pais ou responsáveis, para com os seus filhos);

e) antes de se efetivar a adoção, é necessário fazer um estágio de convivência entre adotando e adotante - este período é dispensado quando a criança é menor de 1 ano ou quando já mora com o adotante.

Mediante essas informações, pode-se perceber que tal processo ainda pode ser considerado longo e complexo, o que acaba por lançar barreiras na iniciativa dos futuros adotantes. Em relação a isso, 
levamos também em consideração que na sociedade ainda temos visões distintas sobre a adoção.

De um lado, há a visão preconceituosa da adoção de que são os laços consanguíneos que unem os membros de uma família, como única forma de possuir laços reais (Gagno \& Weber, 2003), e que os filhos não pertencentes a esse modelo de relação geralmente se tornarão crianças problemáticas. Entretanto, em sentido oposto a esse pensamento, temos a família idealizada, em que reina o respeito e afeto (Vargas, 1998), retomando o conceito de que o que difere nas famílias é unicamente o modo como elas foram constituídas (Gagno \& Weber, 2003).

Nesse foco, é possível relatar que a representação de família é presente no imaginário social como aquela fundamentada em laços consanguíneos, a qual tem a conotação de permanente (Schettini, Amazonas \& Dias, 2006; Sólon, 2006), ou ainda, tendo como aparato até mesmo a Lei Federal n. 9.278 (Brasil, 1990), segundo a qual família é considerada aquela composta por um homem e uma mulher, unidos por matrimônio ou união estável. Mas sabemos que, a partir de todas as modificações no contexto atual, faz-se necessária maior compreensão a respeito das novas relações familiares.

Nesse sentido, devem ser entendidas como família outras formas de ligações afetivas em que existam ou não os padrões considerados tradicionais, ressaltando, portanto, que essa é uma realidade que não possui sua existência independente da sociedade (Sólon, 2006). No contexto deste trabalho, a família em questão foram as famílias adotivas, que podem se configurar em distintas possibilidades, a saber: monoparentais ou unilateral, adoção singular e adoção conjunta feita por casais ou concubinos (Costa \& Rossetti-Ferreira, 2007).

Em geral, independente do modelo em que a família adotiva se constitui, diferentes autores apontam a vivência do processo de adoção como uma questão a ser pesquisada, visto que poucos estudos visam compreender o tornar-se pai e mãe adotivos (Costa \& Rossetti-Ferreira, 2007; Vargas, 1998; Weber, 2008). A fila de espera, especificamente, é considerada um dos pontos fundamentais a serem trabalhados, pois, na maioria dos casos, os futuros pais passam por um período de "gestação psíquica", processo que gera desconforto, temor e ansiedade nas famílias. Isso porque os adotantes se deparam com uma reconstrução do espaço mental para o filho que virá (Campos \& Costa, 2004; D’Andrea,
2002), ainda que nesse tipo de "gravidez" não seja possível definir quando a criança vai nascer/chegar, essa espera indeterminada é realmente difícil, assevera Weber (2008).

Tendo em vista tal discussão, Weber (2009) afirma que a preparação com os pais é necessária, pois assim os adotantes têm a possibilidade de pensar sobre suas motivações, expectativas, medos, desejos, dentre outros, tomando consciência dos limites de si e dos outros, bem como das responsabilidades inerentes à maternidade/paternidade adotiva. Segundo autores como Schettini, Amazonas e Dias (2006) e Reppold e Hutz (2003), é necessário que os adotantes consigam distinguir suas reais motivações conscientes e inconscientes para a adoção, visto que são aspectos essenciais no indicador da qualidade da relação futura entre adotantes e adotandos.

Weber (2003) discute, ainda, que enquanto os pais estão na fila de espera, encontram-se ansiosos, necessitando de um espaço de acolhimento, que geralmente não encontram, pois o ambiente em que estão inseridos é apenas aquele em que são cadastrados, examinados, investigados e interpretados de acordo com seus deslizes dos relatos verbais. De acordo com estudos realizados por Costa e Campos (2003), durante esse processo diferentes aspectos podem ser percebidos na vivência das famílias durante a espera na fila, tais como: ansiedade e temor vs. necessidade de segurança; a demora na conclusão do processo; exposição vs. proteção.

Levando em conta essa situação, Costa e RossettiFerreira (2007) argumentam que esses sentimentos podem vir a aparecer, visto que a transição da parentalidade adotiva tende a ser abrupta, pois nela não há um envolvimento gradual dos pais com seus papéis parentais, passando, dessa forma, por mais tensões que os pais biológicos. Incluem-se, nesse âmbito, as diferentes escolhas que essas famílias têm de fazer durante o processo, algo complexo e multidimensional (Weir, 2003).

Em virtude dessas diferentes informações, podemos perceber que os adotantes vivem a fase de espera com uma tensão carregada de expectativas, preocupações e esperanças (Schettini, 1998). Desse modo, diversos são os estudos que pesquisam sobre adoção (Ducatti, 2003), mas pouco se tem sobre como os adotantes vivenciam o processo de espera pela criança. Portanto, com esta pesquisa buscamos 
verificar os sentimentos dos pais envolvidos no processo da fila de espera da adoção.

\section{Metodologia}

\section{Participantes}

Foram selecionados por conveniência a fazerem parte da pesquisa seis participantes (Quadro 1), dois casais e duas irmãs, com idades entre 37 a 47 anos e com tempo de entrada no processo de adoção variando de dois a cinco anos e meio. Desses, apenas um casal possui filhos biológicos. Todos os participantes faziam parte do Grupo de Apoio a Pais na Fila de Espera da Adoção de uma cidade do interior do Paraná. Para que as questões de sigilo e anonimato sejam respeitadas, os entrevistados serão denominados como "Participante", e numerados de 1 a 6, de acordo com a ordem de produção das entrevistas.

\section{Procedimentos}

Primeiramente, para o desenvolvimento da pesquisa, foi pedida a autorização do Fórum Municipal da cidade alvo do estudo. Nessa ocasião, foram apresentados e explicados os objetivos e os métodos utilizados, assegurando aspectos citados no Termo de Consentimento Livre e Esclarecido (TCLE): anonimato, sigilo e intuito da pesquisa. Garantimos, também, a realização de uma devolutiva dos resultados obtidos para os sujeitos. Após a prévia autorização, a pesquisa foi encaminhada ao Comitê de Ética em Pesquisa com Seres Humanos da Universidade Estadual do Centro-Oeste (Comep/ Unicentro - Protocolo n. 052/2010).

Posteriormente, estabelecemos o contato inicial com os futuros adotantes, o qual ocorreu através do Grupo de Apoio a Pais na Fila de Espera da Adoção, da Comarca em questão. Neste, a pesquisadora realizou conversas informais com os casais sobre a pesquisa, apresentando os aspectos relevantes a esta e convidando todos a participarem. Com o aceite de participação, as entrevistas foram agendadas nos locais de preferência dos participantes.

Após terem lido e assinado o TCLE, as entrevistas foram realizadas em dois momentos distintos. No primeiro momento, as entrevistas aconteceram individualmente. Após esse procedimento, as entrevistas foram realizadas com os pares. Estes foram entrevistados no formato de um tema gerador, que, segundo Meira e Tanamachi (2003), desafia as pessoas envolvidas, buscando a superação das condições propostas no momento. 0 tema abordado foram as reações dos pais caso fossem chamados na fila de espera; a pergunta foi respondida de forma livre.

Como método para a pesquisa, adotou-se uma investigação qualitativa, descrita por Minayo (1994) como uma abordagem que se preocupa com um nível da realidade social que não é possível ser quantificado, pois possui mais riqueza que qualquer dado numérico. Nela estão presentes os significados dos discursos apresentados, bem como o respondente do espaço mais complexo das relações que não podem ser reduzidas a variáveis.

Em relação ao instrumento, utilizamos um roteiro de entrevista semiestruturada que convidou os participantes a falarem livremente sobre o tema, com perguntas abertas, o que, de acordo com Bleger

Quadro 1 - Categorização dos participantes da pesquisa

\begin{tabular}{cccc}
\hline Identificação & Idade & $\begin{array}{c}\text { Filhos } \\
\text { (biológicos ou adotivos) }\end{array}$ & $\begin{array}{c}\text { Tempo de entrada no pro- } \\
\text { cesso de adoção }\end{array}$ \\
\hline Participante 1 & 40 & Não possui & 5 anos e meio \\
Participante 2 & 41 & Não possui & 5 anos e meio \\
Participante 3 & 41 & Não possui & 2 anos \\
Participante 4 & 37 & Não possui & 2 anos \\
Participante 5 & 44 & 2 & 2 anos e meio \\
\hline Participante 6 & 47 & 2 & 2 anos e meio \\
\hline
\end{tabular}

Fonte: Dados da pesquisa. 
(2007), provoca a flexibilidade de poder exigir diversas respostas para a pergunta, de acordo com a personalidade do entrevistado. Considerando os momentos em que o sujeito acaba por fugir do tema proposto, o entrevistador tem a possibilidade de retomá-lo; dessa forma, o indivíduo poderá falar espontaneamente, associando as ideias sugeridas (Silvares, 2006).

Para o tratamento de dados, utilizou-se a análise de conteúdo, a partir da qual é possível encontrar o que está nas entrelinhas do que se fala, como proposto por Bardin (1977). Os dados obtidos foram organizados em categorias e subcategorias, para que houvesse uma melhor compreensão do conteúdo apresentado.

Por meio dessa análise, foram observadas três categorias analíticas: por que adotar; o gestar na fila de espera; e o perfil desejado. Dentro delas, foram subdivididas algumas categorias empíricas, que podem ser observadas no Quadro 2.

\section{Análise dos resultados}

Considerando o restrito número de estudos que abordam o modo como os futuros pais vivenciam o processo de adoção na fila de espera, buscamos observar e analisar questões pertinentes a esse processo, para ampliar a visão sobre a adoção e sobre todos os envolvidos. Devemos ressaltar que os discursos dos entrevistados na pesquisa estão enviesados por suas participações no Grupo de Apoio, que tem a finalidade de um grupo operativo, possibilitando aos pais dividirem seus conflitos, a partir de um conjunto de pessoas com um objetivo em comum, no qual o vínculo entre os membros possibilita o desenvolvimento grupal (Bleger, 2007). Consequentemente, percebe-se, em geral, a expectativa dos sujeitos em relação à espera do filho, demonstrada pelos discursos que chegam a se referir ao processo de adoção como uma gravidez interminável ou, ainda, como uma situação terrível.

\section{Por que adotar?}

A partir dos dados obtidos nas entrevistas com os pais na fila de espera, notamos que a palavra adoção é dotada de diferentes significados, tal como aponta Weber (2008). Desse modo, buscamos abranger os motivos para adotar uma criança, porque compreender o lugar ocupado pela adoção no imaginário dos pais é de suma importância, visto que a relação entre filho adotivo e pais adotantes é influenciada pelas motivações da adoção (Scorsolini-Comin,

Quadro 2 - Categorias de análise

Categorias analíticas
Por que adotar? - Refere-se à visão dos sujeitos sobre os
motivos para a adoção.
O gestar na fila de espera - Diz respeito a como o processo de
adoção é vivenciado pelos participantes.

Qual o perfil desejado? - Descreve como os futuros pais veem seus futuros filhos.

\section{Categorias empíricas}

Por solidariedade: categoria relacionada à percepção dos sujeitos da adoção como caridade ou ato de ajuda.

Por afeto: ligada aos sentimentos descritos pelos participantes, como o amor

A ansiedade: categoria pautada nos sentimentos de angústia e expectativas.

A paciência: categoria que descreve, principalmente, aspectos religiosos e a capacidade de esperar.

A burocracia: categoria que surge a partir dos comentários dos casais, pois muitas vezes não sabem o que causa a demora no processo de adoção.

0 idealizado: nesta categoria os participantes relataram ter expectativas em relação aos aspectos físicos e de relacionamento com seu filho.

O não idealizado: categoria que descreve a não idealização dos participantes em relação a seu filho.

Fonte: Dados da pesquisa. 
Amato \& Santos, 2006). Neste estudo, duas subdivisões foram encontradas: a adoção por solidariedade e por afeto.

Elas se diferenciam de acordo com as vivências, a personalidade e, até mesmo, as crenças dos participantes. A primeira subcategoria está relacionada ao discurso mais voltado ao pensamento de adoção como ideia filantrópica, como se observa na fala do Participante 6: “... ajuda... ajudar uma criança... É, fazer o bem". E também no discurso da Participante 4; "eu acho que adotar seria um acolher. Uma pessoa que não faz parte da família né, ou, do convívio né, que você traz ela pra si".

Esses discursos remetem a outros estudos (Levinzon, 2004; Silva \& Kemmelmeier, 2008; Weber, 2003, 2008) que apresentam a tendência de associar adoção à filantropia ou à caridade. Tais dados são aspectos essenciais no indicador da qualidade da relação futura entre os adotantes e os adotandos. Segundo Levinzon (2004), as motivações para a adoção podem intervir no vínculo parental, pois deve ser claro para os pais o desejo de um filho, e não o anseio de desempenhar caridade.

Weber (2002) cita, ainda, que pais motivados pelo altruísmo podem vir a ser mais críticos em relação a seus filhos, conferindo a eles um número maior de atributos negativos do que os demais pais que tiveram outras motivações para a adoção.

Essa preocupação com as reais motivações para a adoção existe, pois durante muito tempo a prática contemplava unicamente os interesses dos pais adotivos. Porém, ao vermos emergir a cultura de adoção na contemporaneidade, sabemos que deve haver um olhar mais atento. Nesse sentido, busca-se uma prática que favoreça o desenvolvimento do adotado, a fim de que ele possua uma família, e não apenas um abrigo (Gondim et al., 2008).

Em contraponto a essas falas, outros participantes deixam bem definida a classificação da palavra "adoção" por afeto. Como podemos analisar em "... pra gente adotar, no caso é... Compartilhar né, esse amor que a tem pra dar pra alguém..." (Participante 2); "... amor" (Participante 5).

Fica explícita, em ambos os discursos, a descrição do adotar como sinônimo de amor, ou ainda o compartilhar desse sentimento. Tal descrição é percebida também na pesquisa apresentada por Weber (2008), na qual a expressão "amor" aparece como a primeira associação à palavra "adoção".
Ayres (2009) assevera que tal sentimento pode ser considerado a espinha dorsal das relações saudáveis de parentalidade, sejam elas biológicas ou não. Esse ponto também é demonstrado por Weber (2003), ao citar que o amor é uma relação em que as pessoas envolvidas andam unidas para adotarem-se umas às outras. Esse autor considera tal sentimento como o fator principal para uma adoção recíproca em que as relações futuras possam ser bem-sucedidas.

\section{0 gestar na fila de espera}

Essa categoria revela como os adotantes vivem a fase de espera da adoção, um momento de tensão, carregado de expectativas, preocupações e esperanças, como citam Schettini (1998) e Campos e Costa (2004), superando os aspectos legais e jurídicos do processo. Tais pontos podem ser percebidos nas falas dos participantes, as quais foram divididas em subcategorias denominadas como: a ansiedade, a paciência e a burocracia. Na primeira, podemos perceber na maioria dos futuros pais a angústia e as expectativas presentes nesse momento de espera: "... é um pouco agoniante, né? Porque a gente não sabe se vai dar certo, não vai, se vai demorar meses, se vai demorar um ano, dez anos, né? É tempo indeterminado" (Participante 3); "... é aquela gravidez que você tá esperando, esperando... Sabe e ela nunca termina, e ela nunca acaba..." (Participante 1).

Esses aspectos podem ser percebidos em razão da indeterminação temporal causada pelo processo de gestação adotiva (Gondim et al., 2008), a qual, na maioria das vezes, torna a espera pela chegada da criança uma vivência dolorosa, marcada principalmente pela angústia da incerteza. Nesse processo, os adotantes se deparam com uma reconstrução do espaço mental para o filho que virá (Campos \& Costa, 2004; D’Andrea, 2002), tornando a expectativa constante na vida dos sujeitos.

Em virtude desses sentimentos e da falta de aspectos concretos como em uma gestação usual, os adotantes buscam elementos que simbolizem a espera, tal como o toque do telefone (Weber, 2008). Esse ponto é demonstrado no discurso de um dos participantes que cita as ligações como uma simbolização da espera. "... Aí de repente toca o telefone, é alguém do fórum... Ah, precisa vir aqui e tal e tal. Você fica naquela expectativa..." (Participante 1). 
Na segunda subcategoria, definida como paciência, podemos observar na fala de uma das participantes a conformidade com a espera, possivelmente ligada à resignação perante a demora do processo. Essa submissão, em alguns casos, está atrelada também ao medo dos pais de que seus processos não sejam resolvidos, caso demonstrem sua insatisfação com a justiça: "... eu acho que é, um período, espera né. E que você tem que ter, tem que criar paciência..." (Participante 4).

O papel do divino, como citam Costa e Campos (2003), também esteve presente no discurso dos participantes, vinculado à paciência na espera pelo filho. De modo geral, essa é uma alternativa comumente utilizada pelas pessoas, em especial aquelas que tiveram uma educação fundamentada na religiosidade (Silva \& Kemmelmeier, 2008).

... creio muito em Jesus Cristo e eu creio na Virgem Maria, sabe? Eu peço muito pra ela, que um dia, da mesma maneira que ela teve o filhinho dela e que o segurou, um dia eu vou ter o meu. Vou segurar o meu... (Participante 1).

De acordo com Baltazar (2003), a religiosidade cumpre a função de uma compensação simbólica consoladora, atrelada na adoção à justificativa para permanecer acreditando na resolução do processo e na motivação para adotar uma criança. Isso porque, como mencionamos anteriormente, sabemos que essa espera é marcada por angústias - aliviadas e ressignificadas pelas crenças.

A última subcategoria, relacionada à burocracia dos processos, foi apresentada por todos os participantes da pesquisa. Eles citam que um dos sentimentos existentes no estar na fila de espera são a indignação e a revolta pelo descaso da justiça com as crianças abrigadas e seus processos, como podemos perceber nos discursos: "... é uma revolta, né? De saber que tem tanta criança né, que poderia estar numa família e estão crescendo num abrigo, né? Por pura burocracia, por, por falta de agilizarem esses processos..." (Participante 5);“... Parece que a Justiça... Vai embolando o negócio, vai ficando uma burocracia danada né, pra resolver..." (Participante 2).

Esse entrave no processo de adoção é citado por autores como Weber (2008) e Levinzon (2004) como responsável pela situação árdua em que os futuros pais e as crianças estão inseridos. A burocracia gera turbulências psíquicas, tendo como consequências até mesmo a desmotivação para prosseguir com o processo ou, ainda, a falta de incentivo a novos interessados na adoção.

Contudo, mesmo a partir dessas falas, devemos retomar o fato de que não somente a justiça é culpada pela lentidão no desenrolar dos processos, pois ainda é notória no Brasil a série de preferências por parte dos adotantes em relação ao perfil das crianças a serem adotadas. A maioria das pessoas que entram com pedido de adoção idealiza uma criança muito distante da presente na realidade das instituições brasileiras, o que consequentemente cria duas filas desproporcionais: uma de pais à espera de um filho, e outra de muitas crianças à espera de um lar (Weber, 2008).

\section{Qual o perfil desejado?}

A questão dos anseios e desejos dos pais na escolha da criança ainda é muito debatida, segundo Weber (2003). Tendo em vista a relevância dessa discussão, abordamos, pela análise das falas dos sujeitos, duas subdivisões referentes às características desejadas nos futuros filhos adotivos: a representação do filho idealizado e a do não idealizado. A primeira está pautada nas expectativas físicas e de relacionamento com o filho, diretamente relacionadas às características inseridas no processo de adoção.

Sabemos que não somente nos processos de adoção, mas também na gestação dos filhos biológicos, os pais falam, imaginam e representam uma criança antes mesmo de seu nascimento (Fagundes Netto \& Duarte, 2010). Esse filho supostamente concretizará todos os sonhos e desejos que os pais não foram capazes de realizar.

Durante a adoção, autores como Amin e Menandro (2007), Levinzon (2004) e ScorsoliniComin, Amato e Santos (2006) citam essa constante idealização, mencionando que pode haver, por trás dessa fantasia, o desejo de um filho perfeito, sem problemas de saúde e de comportamento facilmente moldável pelos adotantes (Gondim et al., 2008), visto que eles têm o poder de escolher as características da criança. Tais fatores podem ser percebidos nos discursos dos participantes: "... quando eu pensava em adotar uma criança, eu queria uma menina, e nunca bebê... Eu pensei numa criança que corresse pela casa, que falasse errado..." (Participante 5); "... eu acho que assim, a gente cria um mundo 
maravilhoso. De amizade, de alegria, companheirismo né... Num mundo assim, companheiro, conversar abertamente e com carinho, amor" (Participante 3).

A partir desses desejos, Sonego e Lopes (2009) comentam que a supervalorização da criança pode ser tão prejudicial quanto sua desvalorização, pois ela ficará sem espaço diante dos pais para ser aceita com seus defeitos e qualidades. Assim, é necessário que o repensar sobre o filho desejado seja constante, pois, sendo ele adotivo ou biológico, os pais devem estar preparados para o filho possível e real, para que a relação entre os desejos e frustrações possa ser compreendida e aceita, reduzindo, assim, a possibilidade de um possível sofrimento de pais e filhos.

Em contraponto a isso, temos a não idealização dos participantes: "... aquela criança que Deus colocar no meu caminho, é essa que eu quero..." (Participante 1).

No discurso da Participante 1, o não fantasiar está intimamente relacionado a aspectos religiosos, analisados na categoria referente à paciência no gestar na fila de espera, podendo aparecer, de acordo com Silva e Kemmelmeier (2008), como uma maneira de aliviar as tensões e ansiedades causadas pelo processo. Outro fator discutível na não idealização pode estar relacionado ao tempo de espera pela adoção, o qual pode vir a causar nos adotantes a descrença na resolução de seus processos e, consequentemente, o medo da frustração, caso o filho demore ainda mais a "nascer".

Uma questão que chamou atenção durante a pesquisa foi a do tema gerador, em que os pais demonstraram suas possíveis reações em relação à chegada do filho. Ao serem questionados sobre como seria se eles fossem chamados pelo Fórum para buscarem a criança, todos responderam com entusiasmo, corroborando com as ideias anteriormente citadas, a respeito das expectativas geradas em torno do processo de adoção, ilustradas pelas falas do casal dos participantes 5 e 6: "... Você quer que eu comece a chorar já? Só de imaginar uma coisa dessas já me dá vontade de chorar...”; “... Nossa, nós corria já! Iria ser... Ó, iria ser o maior presente que nós íamos ganhar...".

Nesse momento, percebemos que a angústia presente durante a entrevista foi suavizada na realização desse questionamento aos participantes, pois o foco da espera era deixado de lado para uma perspectiva da possível concretização do desejo.

\section{Considerações finais}

A partir da análise dos aspectos mais relevantes que emergiram nas entrevistas, algumas considerações acerca da temática abordada puderam ser repensadas à luz do referencial teórico que fundamentou e sustentou o presente artigo. A realização desta pesquisa confirmou que, de fato, ainda existem muitos pontos a serem trabalhados em torno da adoção, pois se trata de um tema constituído por diversos percalços que dificultam e tornam esse processo doloroso para todos os envolvidos.

Nos casos aqui discutidos, uma manifestação muito presente durante as entrevistas foi a religiosidade, uma alternativa geralmente utilizada pelos pais para diminuírem suas expectativas a partir de uma simbolização consoladora. Tal fator talvez tenha sido influenciado pela educação fundamentada na religião, muito perceptível na cidade investigada.

Mesmo sendo uma pesquisa com um grupo pequeno de participantes, foi possível perceber que os sujeitos supostamente menos envolvidos com o processo da adoção responderam sobre seus motivos, como um ato de solidariedade. Possivelmente, esse fator apareceu em seus discursos por terem aceitado a adoção dado o desejo do parceiro ou, ainda, por questões religiosas em demonstração de benevolência e altruísmo. Por outro lado, aqueles que demonstraram maior ansiedade e citaram a adoção como um ato de amor evidenciaram maiores expectativas quanto à chegada da criança.

Tais aspectos retomam a concepção de que o amor pode ser considerado um dos principais pontos para uma relação saudável de parentalidade, pois, a partir dele, as pessoas envolvidas marcham unidas para adotarem-se umas às outras.

Destacamos que os participantes foram escolhidos de um grupo de apoio a pais, o que talvez tenha influenciado seus discursos, pois o grupo possibilita aos casais um espaço para discutirem suas vivências, permitindo-lhes a ressignificação e a elaboração da situação em questão. Esse panorama possivelmente fez que as falas dos sujeitos fossem diferenciadas do 
discurso dos pretendentes à adoção que não fazem parte de um grupo.

Desse modo, afirmamos a importância do compartilhamento de possibilidades, desejos e experiências, a partir do olhar do outro, o que caracteriza uma significante instância de mudanças potenciais na vivência pela espera do filho. Podemos, portanto, considerar que os grupos de pais têm sido um instrumento relevante de inserção da Psicologia no acompanhamento dos futuros pais no processo de adoção, bem como aberto novas possibilidades de pesquisa e atendimento.

Como já exposto anteriormente, a literatura sobre a temática de como os pretendentes à adoção vivenciam esse processo ainda é muito escassa. É necessário abrir espaço para diversas pesquisas, dentre elas sobre a importância do acompanhamento de uma equipe técnica durante a espera e após concluído o processo de adoção, visto que os próprios participantes sugeriram esse olhar mais abrangente, a fim de que as adoções possam ser vivenciadas com menos sofrimento para pais e filhos.

\section{Referências}

Amin, I. D., \& Menandro, P. R. M. (2007). Preferências por características do futuro filho adotivo manifestada por pretendentes à adoção. Interação em Psicologia, 2(11), 241-252.

Ayres, L. S. M. (2009). Adoção: De menor a criança, de criança a filho. Curitiba: Juruá.

Baltazar, D. V. S. (2003). Crenças religiosas no contexto dos projetos terapêuticos em saúde mental: Impasse ou possibilidade? Dissertação, Mestrado em Saúde Pública, Fundação Oswaldo Cruz, Rio de Janeiro. PMCid:1223809.

Bardin, L. (1977). Análise de conteúdo. Lisboa: Edições 70.

Bleger, J. (2007). Temas de psicologia: Entrevista e grupos. São Paulo: Martins Fontes. PMid:17705206.

Brasil. (1990). Lei n. 8.069, de 13 de julho de 1990. Dispõe sobre o Estatuto da Criança e do Adolescente e dá outras providências. Diário Oficial [da] República Federativa do Brasil. Brasília, DF. Recuperado em 18 jan. 2013, de http://www.planalto.gov.br/ccivil_03/ leis/L8069.htm
Brasil. (2009). Lei n.12.010, de 3 de agosto de 2009. Dispõe sobre as novas diretrizes para a adoção no Brasil, à convivência familiar e as garantias dos adotandos. Diário Oficial [da] República Federativa do Brasil. Brasília, DF. Recuperado em 22 out. 2010, de http://www.planalto.gov.br/ccivil_03/_ato20072010/2009/lei/112010.htm

Campos, N. M. V, \& Costa, L. F. (2004). A subjetividade presente no estudo psicossocial da adoção. Psicologia: Reflexão e Crítica, 17(1), 95-104. doi:10.1590/ S0102-79722004000100012.

Costa, L. F., \& Campos, N. M. V. (2003). A avaliação psicossocial no contexto da adoção: Vivência das famílias adotantes. Psicologia: Teoria e Pesquisa, 19(3), 221230. doi:10.1590/S0102-37722003000300004.

Costa, N. R. A., \& Rosseti-Ferreira M. C. (2007). Tornarse pai e mãe em um processo de adoção tardia. Psicologia: Reflexão e Crítica, 20(3), 425-434. doi:10.1590/S0102-79722007000300010.

D’Andrea, A. (2002). 0 casal adotante. In M. Andolfi. A crise do casal: Uma perspectiva sistêmico - relacional (pp. 233-247). Porto Alegre: Artmed.

Ducatti, M. (2003). A tessitura inconsciente da adoção. São Paulo: Casa do Psicólogo. PMid:12972059.

Fagundes Netto, M. V. R., \& Duarte, L. S. (2010). Frankenstein na UTI neonatal: 0 conflito entre o filho real e o filho imaginário. Psicanálise \& Barroco em Revista, 8(1), 175-188.

Gagno, A. P., \& Weber, L. N. D. (2003). A adoção na mídia: Revisão da literatura nacional e internacional. Paidéia, 13(25). doi:10.1590/S0103-863X2003000200010.

Gondim, A. K., Crispim, C. S., Fernandes, F. H. T, Rosendo, J. C, Brito, T. M. C, Oliveira, U., et al. (2008). Motivação dos pais para a prática da adoção. Boletim de Psicologia, 58(129).

Levinzon, G. K. (2004). Adoção. São Paulo: Casa do Psicólogo.

Meira, M. E. M., \& Tanamachi, E. R. (2003). A atuação do psicólogo como expressão do pensamento crítico em psicologia e educação. In M. E. M. Meira \& M. A. M. Antunes. Psicologia Escolar: Práticas Críticas (pp. $27-$ 61). São Paulo: Casa do Psicólogo. 
Minayo, M. C. S. (1994). Pesquisa Social: Teoria, método e criatividade. (6a ed.). Petrópolis, RJ: Vozes.

Reppold, C. T., \& Hutz, C. S. (2003). Reflexão social, controle percebido e motivações à adoção: Características psicossociais das mães adotivas. Estudos de Psicologia, 8(1), 25-36. doi:10.1590/ S1413-294X2003000100004.

Schettini, L. F. (1998). Compreendendo os pais adotivos. Recife: Bagaço. PMCid:28089.

Schettini, S. S. M., Amazonas, M. C. L. A., \& Dias, C. M. S. B. (2006). Famílias adotivas: Identidade e diferença. Dossiê - Psicologia e Saúde 11(2), Maringá, 285-293.

Scorsolini-Comin, F., Amato, L. M., \& Santos, M. C. (2006). Grupos de apoio para casais pretendentes à adoção: A espera compartilhada do futuro. Spagesp, 7(2).

Silva, A. M., \& Kemmelmeier, V. S. (2008). O mito da adoção tardia: As vivências de famílias que adotaram adolescentes no momento certo. Monografia, Curso de Psicologia, Universidade Estadual do Centro Oeste, Irati, PR.

Silvares, E. F. M. (2006) Atendimento psicológico em clínicas-escola. Campinas: Alínea.
Sólon, L. A. G. (2006). A perspectiva da criança sobre seu processo de adoção. Dissertação, Mestrado em Filosofia, Universidade de São Paulo, Ribeirão Preto, SP.

Sonego, J. C., \& Lopes, R. C. S. (2009) A experiência da maternidade em mães adotivas. Aletheia: Revista de Psicologia 29, 16-26.

Vargas, M. M. (1998). Adoção tardia: Da família sonhada à família possível. São Paulo: Casa do Psicólogo.

Weber, L. N. D. (2002). Pais e filhos por adoção: Um amor conquistado. Recuperado em 1 nov. 2010, de http:// www.mp.rs.gov.br/infancia/doutrina/id190.htm

Weber, L. N. D. (2003). Aspectos psicológicos da adoção. Curitiba: Juruá.

Weber, L. N. D. (2009). Laços de ternura: Pesquisa e histórias de adoção. Curitiba: Santa Mônica. doi:10.1590/ S1517-97022009000200003.

Weber, L. N. D. (2008). Pais e filhos por adoção no Brasil: Características, expectativas e sentimentos. Curitiba: Juruá.

Weir, K. N. (2003). Adoptive family "leap-frogging" patterns. Adoption Quarterly, 7(1), 27-41. doi:10.1300/ J145v07n01_03. 